\title{
Evaluation of the Advanced Minning Front Craft in and around National Parks of the Benue and Bouba-Ndjidda in North Cameroon
}

\author{
Aoudou Doua Sylvain1, Narke Jean Cyrille², Mayen Ndiong Bertille ${ }^{3}$ \\ ${ }^{1}$ The National Advanced School of Engineering of Maroua, Maroua, Cameroon \\ ${ }^{2}$ National Institute of Cartography, Yaoundé, Cameroon \\ ${ }^{3}$ GIZ (Deutsche Gesellschaft Für Internationale Zusammenarbeit), Yaoundé, Cameroon \\ Email: aoudoudoua@yahoo.fr, cyrille_narke@yahoo.fr, bertille.mayen@giz.de
}

How to cite this paper: Sylvain, A.D., Cyrille, N.J. and Bertille, M.N. (2018) Evaluation of the Advanced Minning Front Craft in and around National Parks of the Benue and Bouba-Ndjidda in North Cameroon. Journal of Geographic Information System, 10, 461-475.

https://doi.org/10.4236/jgis.2018.104024

Received: July 6, 2018

Accepted: August 21, 2108

Published: August 24, 2108

Copyright $(9) 2018$ by authors and Scientific Research Publishing Inc. This work is licensed under the Creative Commons Attribution International License (CC BY 4.0).

http://creativecommons.org/licenses/by/4.0/

\begin{abstract}
This study focuses on the assessment of "the advancement of the mining front (gold panning) in and around protected areas". The aim of this article is to evaluate, using geomatics tools, the recent advance of the mining front (gold panning) in Benue National Park (PNB) and Bouba-Ndjidda (PNBN) for their planning purposes. We adopted a methodological approach articulated from the field surveys to the processing of satellite images and the integration of the data into a GIS. Thus, 30 gold panning sites were visited, including 16 in the PNB and 14 in the PNBN. From the mapping of the pressures exerted by this activity, it appears that $143.8 \mathrm{~km}$ and $73.8 \mathrm{~km}$ of cumulated linear were exploited respectively in the GNP and the PNBN; moreover, the results allowed us to detect that the surfaces degraded by gold panning are more important in Benue than in Bouba Ndjidda. The massive influx of migrants from the more populated areas of the Far North of Cameroon as well as neighboring countries (Chad, Nigeria and the Central African Republic) has not only brought about the growth of a pioneering agricultural front, but also the mining front, following the gold rush from 2009; which has led to huge environmental consequences in these protected areas.
\end{abstract}

\section{Keywords}

Mining Front, Artisanal Mining Front, National Parks, Benue

\section{Introduction}

Africa is rich in important natural resources, mainly mining. The share of African world production of gold is estimated at $25 \%$ [1]. In recent years, due to its 
high price, underground gold prospecting has multiplied and spread to desert regions that were previously under-explored [2] [3]. The mining sector in several African countries has made significant investments, mainly driven by World Bank reforms in the 1990s and 2000s, and by a relaxation of the national mining codes and its high course [4]. Thus the semi-mechanized, mechanized and artisanal exploitation intensified.

In Cameroon, despite of an enviable potential, the activity is dominated by artisanal mining, known as gold panning, which is being smuggled. It is defined as being "any exploitation whose activities consist in extracting and concentrating mineral substances using manual methods and processes and little mechanized" (Law N ${ }^{\circ}$ 2016/2017 bearing Cameroon Mining Code of December 14, 2016). This has been practiced for several decades by thousands of people. The contribution of these extractive activities remains insignificant in the country's economy (around 1\% of GDP). The quest for prospecting and mining has expanded and intensified in the North Cameroon region.

With its remarkable biodiversity and the richness of its subsoil, the region of North Cameroon is the scene of several socio-economic and environmental issues [5]. Indeed, more than $40 \%$ of its surface area is subject to a nature protection regulation (3 national parks-Benoue, Bouba Ndjidda and Faro, 28 areas of hunting interest (ZIC)). The sustained population increase from $7.5 \mathrm{hab} / \mathrm{km}^{2}$ in 1976 to $31 \mathrm{hab} / \mathrm{km}^{2}$ in 2010 (RGPH) can be explained by the massive influx of migrants from the more populated areas of the Far North of Cameroon [6] [7]. This increase in population is accompanied by the progression of a pioneering agricultural front first and then mining which have major environmental consequences, especially for protected areas. While agriculture was the main activity in the region, gold panning was previously marginal.

But for two decades, the rise in the world price of gold on the world market and the development of new techniques has already resulted in a real "gold rush" thereby boosting this activity, which is developing at the same time. Periphery and progresses are in national parks, in this case, Benoue and Bouba Ndjidda. It constitutes with poaching the greatest threats to the conservation of biodiversity in these protected areas. This "gold fever" has grown so much that we have moved from small, isolated camps of artisanal miners to truly small, well-structured villages.

This situation makes it necessary to make an inventory of this activity in and around the protected areas of this region of Cameroon (Figure 1). The objective of this article is to evaluate the recent progress of the mining front (gold panning) in the Benoue and Bouba Ndjidda National Parks. This is to follow the pressure zones in and around the national parks of Benoue and Bouba-Ndjidda (gold panning sites).

\section{Study Framework}

The BPN and BNPN were created by Pierre FLIZOT, French hunting inspector, 

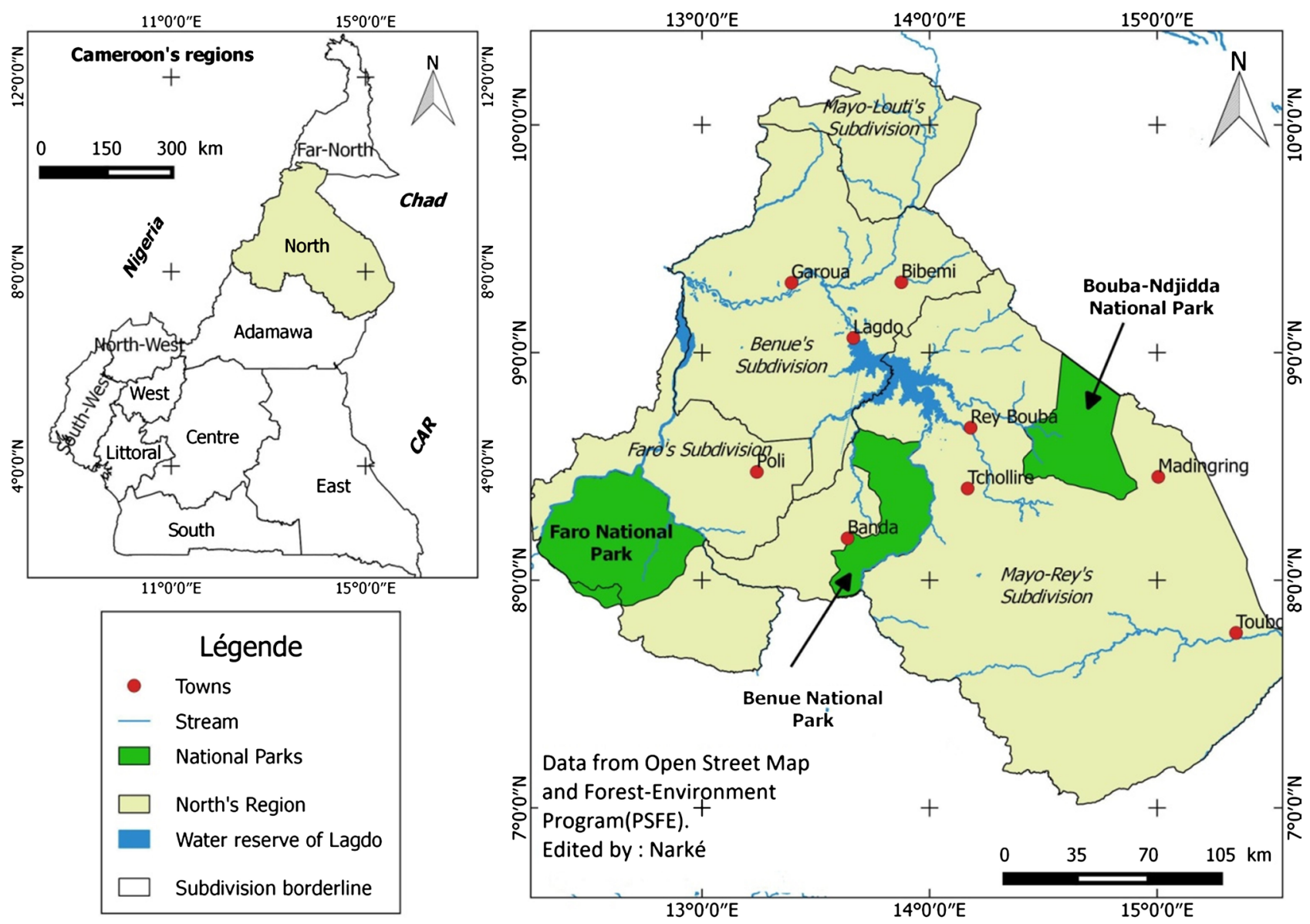

Figure 1. The network of national parks in the Northern Region.

classified as a wildlife reserve respectively by decree $\mathrm{N}^{\circ} 34 / 32$ of November 11th, 1932 and by decree $\mathrm{N}^{\circ} 270$ of July 29th, 1947 of the high commissioner of the French Republic in Cameroon. After independence, the Cameroonian State erected the Benue Wildlife Reserve in Benue National Park by Order No. 86/SDR/DEFC of 21 October 1969, while the Bouba-Ndjidda Wildlife Reserve was transformed into a park a year earlier by decree $N^{\circ} 120 /$ SFDR of 05 December.

The BNNP extends between latitude $08^{\circ} 21^{\prime} \mathrm{N}$ and $09^{\circ} 00^{\prime} \mathrm{N}$, and longitude $14^{\circ} 25^{\prime} \mathrm{E}$ and $14^{\circ} 55^{\prime} \mathrm{E}$. With an area of approximately 220,000 ha, it is limited: to the north by the international border between Cameroon and Chad; in the West by ZIC 11 and Mayo Vaimba and Bidjou; in the East by ZIC 23; in the south-west by the Hosséré Koum mountain range and the $\mathrm{ZIC} \mathrm{N}^{\circ} 10$ and finally in the south by the northern limit of the ZIC N ${ }^{\circ} 12$ constituted by the section of track which links the villages Koum, Mayo Djarendi and the hosséré Koum about $15 \mathrm{~km}$ [8] [9]. The peripheral zone of the park includes five ZICs and mundane areas that serve as a buffer zone.

Administratively, BNP and BNNP are located in the Northern Region. It is located in the Mayo Rey Sub-Division.

The altitude of the study area varies between 200 and more than $2000 \mathrm{~m}$. 
Three sets of reliefs stand out: the imposing Poli massif which rises to $2049 \mathrm{~m}$ and the inselbergs which reach more than $1000 \mathrm{~m}$; low parts, between 200 and $500 \mathrm{~m}$ which slope down towards the Benue valley and Mayo-Rey. To these elements of reliefs are added piedmonts presenting erosion glacis, interfluves battleships. The variety of morpho-topographic features that follow an altitudinal gradient determines the distribution of gold panning activities in and around these protected areas [10] [11].

BNP and BNNP are subject to a contrasting Sudanese climate. The region is marked by a transitional climate between the southern Sudanese climate further south and the dry Sudanese climate [12]. It is limited by the annual isohyets 1000 and $1500 \mathrm{~mm}$. This climate is characterized on the one hand by strong sunshine and a small annual thermal amplitude and on the other hand by the monomodal distribution of precipitation. This results in the regular succession of a dry season of 6 months from November to April and a rainy season of 6 months from late April to mid-October. The average annual temperature is $28^{\circ} \mathrm{C}$, while the maximum temperature is $35^{\circ} \mathrm{C}$, the minimum is $21^{\circ} \mathrm{C}$. This climate punctuates the nature of gold mining methods. In the rainy season, alluvial exploitation is abandoned in favor of the exploitation of the slopes.

The geologic bedrock of the region consists essentially of crystalline rocks, crystallophyllian rocks and quaternary deposits. The heterogeneity of the source rocks establishes the primary gold found in these source rocks, the intense erosion activity on the other hand promotes the establishment of placer gold.

Soils in the study area were studied by Brabant, Humbel and Gavaud [13]. They distinguish the raw mineral soils; poorly evolved soils (erosion, intake); tropical ferruginous soils (modal, concretion or indurated); the fersiallitic soils; tropical soils leached; hydromorphic soils (pseudogley, amphigley) and sodium soils.

The study area is highly dissected by a dense hydrographic network. It includes a main collector, Benue. Its main tributaries are: mayo Mbam and Mayo Kout, Mayo Boulem and Mbay, Mayo Rey and Mayo Godi. The density of the hydrographic network provides a receptacle for alluvial gold resulting from erosion.

\section{Methodology}

Spatial remote sensing monitoring of the mining front in protected areas is based on a methodological approach based on field surveys to the processing of satellite images and the integration of all data in a GIS. For each year and authorizing the diachronic analysis. The different runs on the sites that took place from September 23 to October 25, 2016. The active sites have been the subject of systematic surveys. For each site visited, several elements are recorded by GPS: the position of the camps that serve as base life where the gold miners sleep, the downstream and upstream ends of the site that almost always extend in the axis of a watercourse, the width of the area worked. The data collected is transferred 
to a database under GIS and then completed by a scanning of the surfaces and data input tables (date of the mission, characterization of the sites surveyed...). Their treatment made it possible to map the areas worked from one year to the next and impacted by the gold activities.

To understand the evolution of mining activity on the territory, it needed a "chronological boundary" which was set in 2009, the period of the "rush". We used LANDSAT7-ETM and LANDSAT8-OLI satellite imagery to reconstruct and analyze the mining activity for the years 2009, 2010, 2012, 2014 and 2016. These image data are available on the open access websites (University of Maryland (USA) Global Land Cover Facility (GLCF) and Earth Explorer). The spatial resolution of $30 \mathrm{~m}$ was largely sufficient for the study.

The general principle of the extraction method is inspired by the method based on the use of contrasts between the observed object and its environment [14]. These contrasts are amplified by calculation methods under QGIS to isolate the objects studied and better identify them. Once identified, they are extracted from the images as vectorized data to feed the GIS. The validation of this analysis required the comparison of all the sectors identified by this remote sensing method with the data collected on the sites as well as the photo-interpretation of google earth images of very high resolution. This made it possible to dismiss certain points wrongly identified as mining activity (natural erosion, cultivated areas, bare soil, etc.

\section{Results}

\subsection{Operating Modes}

There are two mine extraction methods in both protected areas (PA) and their peripheries: primary rock mining and alluvial mining.

The first is through vertical circular wells and side or underground galleries. These then organize themselves into a constellation of clusters in the landscape. The construction of the well is done in two phases. The first phase consists in digging a vertical hole whose variable depth and diameter can reach 10 to $30 \mathrm{~m}$ and 2 to $30 \mathrm{~m}$ depending on the terrain. The second phase is reduced to digging a horizontal or inclined gallery that follows the estimated gold vein. The inner walls of the wells are progressively supported by hundreds of tree trunks to provide support to prevent landslides and landslides.

The alluvial exploitation takes place along the rivers or on alluvial terraces. Their spatial organization is linear in space. Here, the miners dig in small beds, on the banks or on the terraces small wells of circular or rectangular shapes of small diameter (maximum $2 \mathrm{~m}$ ).

\subsection{Distribution of Miners in the BNP and BNNP}

The activity began timidly a little over 10 years ago. It intensified less than ten years ago with a large influx of miners. There are approximately 7160 gold washers in both protected areas and their peripheries with an age range between 
35 and under 60 years. Most miners are poorly educated. Some have been to primary school, very little to high school. In the BPN and its periphery, it is estimated at the time of the survey to 1055 the number of miners encountered on the 16 sites visited. This figure may be relatively below reality. The site of Djaba village which is located near the national road $\mathrm{N}^{\circ} 1$ is the most active and has more gold panners at the moment with about three hundred operators. There is a population of gold miners of between 50 and 100 people. This is the Sakdje village site, Mayo Salah 2 and Mboukma large yard. This last site at the time of its rise counted more than 1000 people.

The BNPN has at the time of the survey 6105 miners encountered in the 14 sites visited. Thus, the border worksite operated by Chadian gold panners who are located near the border, precisely about $12 \mathrm{~km}$, has more gold panners at the moment with about 5000 people, if not more. It is followed by some sites whose size of the operators does not reach two cents, it is about: Mayo Waimba, Tokor, Taobawa, Tokormayne...

Several ethnic groups engage in gold panning activity in both PAs. Some groups have a long history of mining crafts like the Gbaya, alongside these are the Dii, indigenous whose main activity before the gold rush was agriculture, mainly yam (white gold of the plain). Migrants from the far north region are discovering this new activity. Besides the nationals, there is a strong colony of Chadians.

\subsection{Mapping of Exploited Surfaces in and around BNP, BNNP and Their Periphery}

The results of this cartographic study are presented in the form of five maps that illustrate the areas affected by gold panning activity (Figure 2 and Figure 3 ). It shows that the activity that started timidly has grown over time. The analysis of the mapping results reported in Table 1 shows that: from 2009, it is estimated that about 529 hectares the area degraded by this activity. It reached the peak of about 735 hectares in 2014 before experiencing a fall in activities in 2016 with about 158 hectares of surfaces degraded by illegal gold panning. This slight decrease in activities is linked to the increase in repressive measures (eviction,

Table 1. Balance of linear and degraded surfaces by gold panning.

\begin{tabular}{ccccc}
\hline \multicolumn{2}{c}{ BNNP } & \multicolumn{2}{c}{ BNP } \\
\hline Année & Surface (ha) & Linear $(\mathrm{km})$ & Surface (ha) & Linear (km) \\
\hline 2009 & 84.2 & 12.2 & 529.1 & 34.9 \\
2010 & 341.5 & 22.6 & 353.2 & 34 \\
2014 & 237.05 & 11.8 & 735.6 & 27.0 \\
2015 & 167.2 & 14.09 & 365.8 & 28.6 \\
2016 & 216.6 & 13.2 & 158.5 & 19.8 \\
Total & & 73.8 & & 143.8 \\
\hline
\end{tabular}

Source: Satellite image processing, Landsat 7 and Landsat 8. 

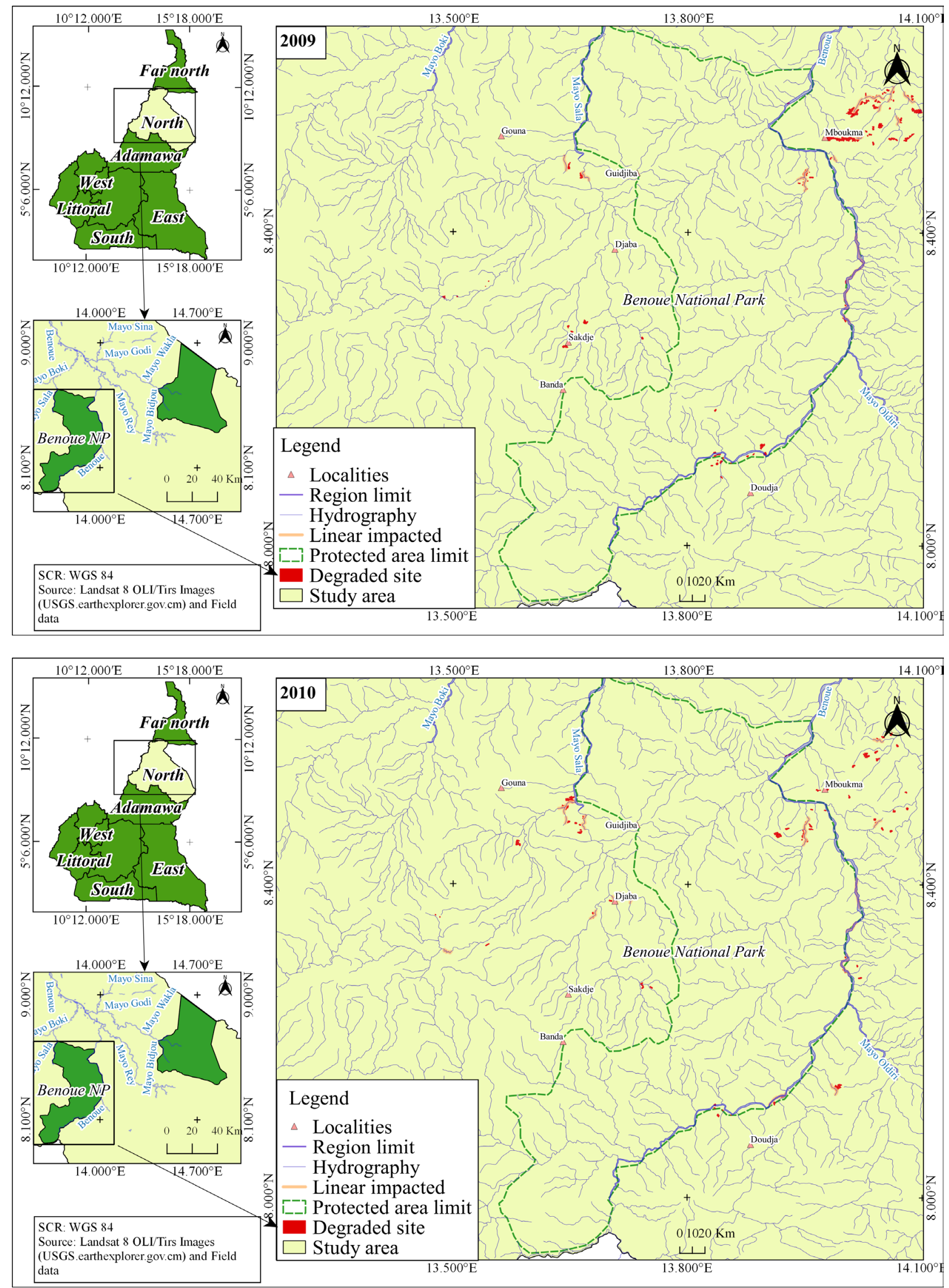

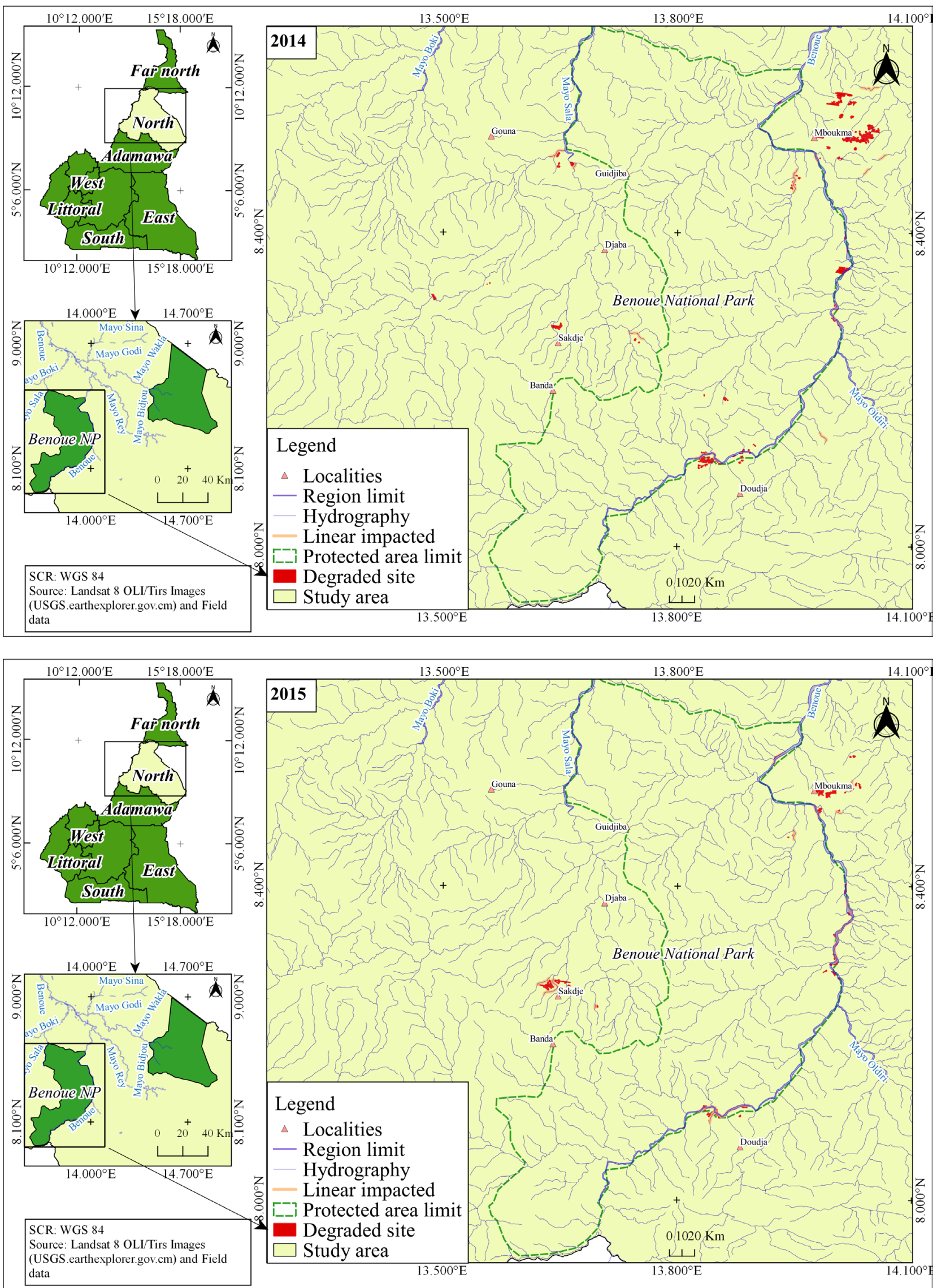


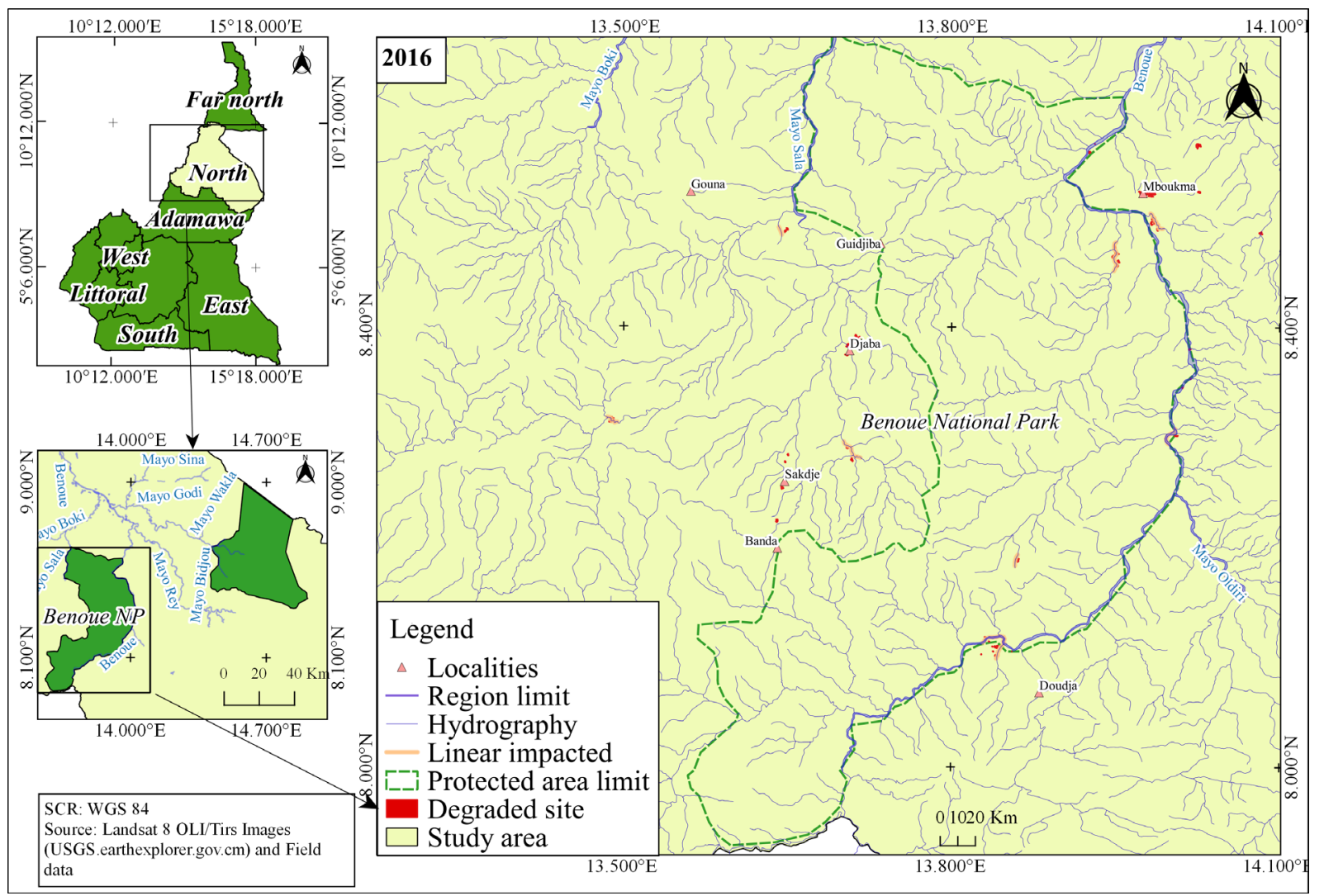

Figure 2. Mapping exploited areas from 2009 to 2016 in the BNP and its periphery.

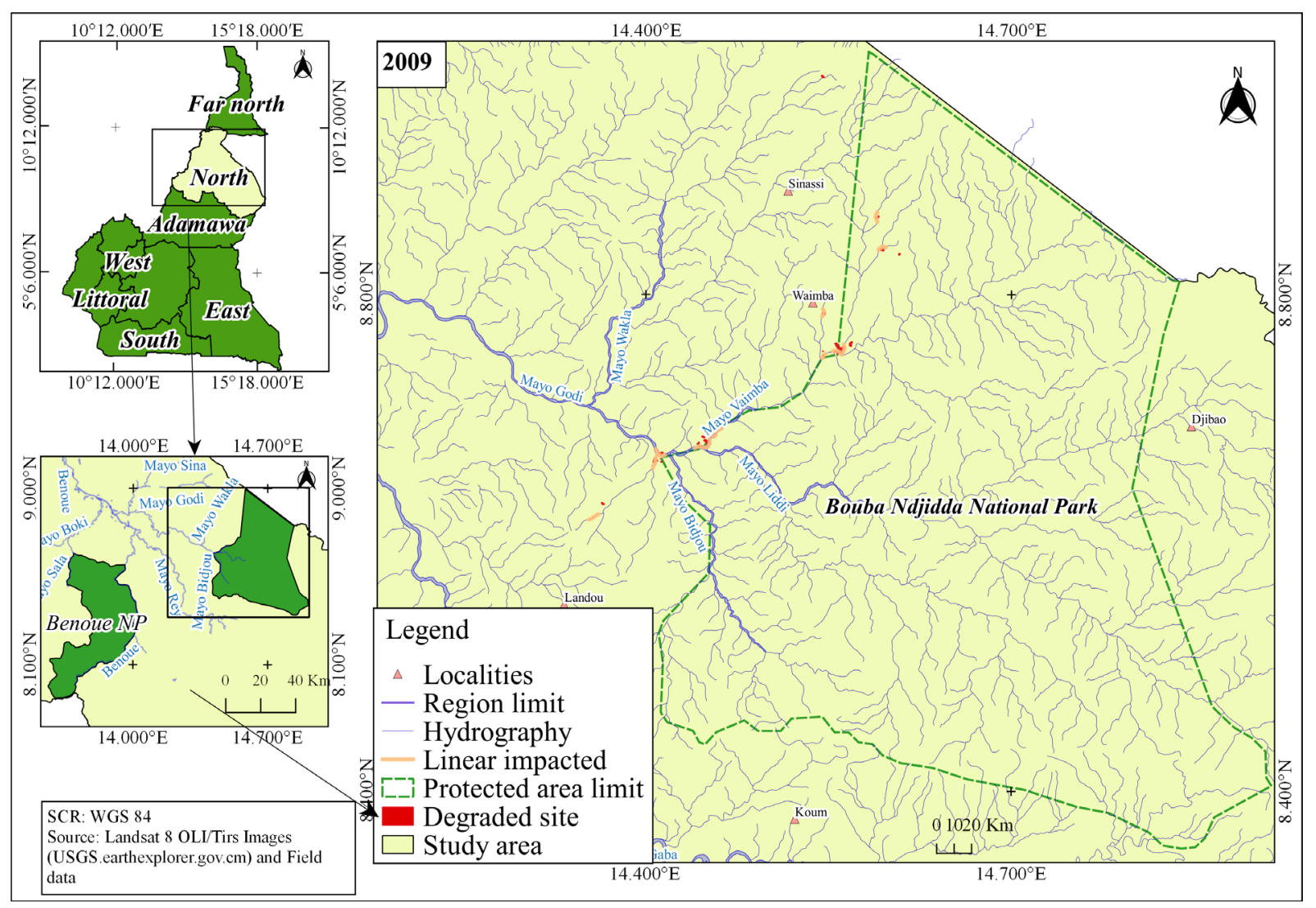



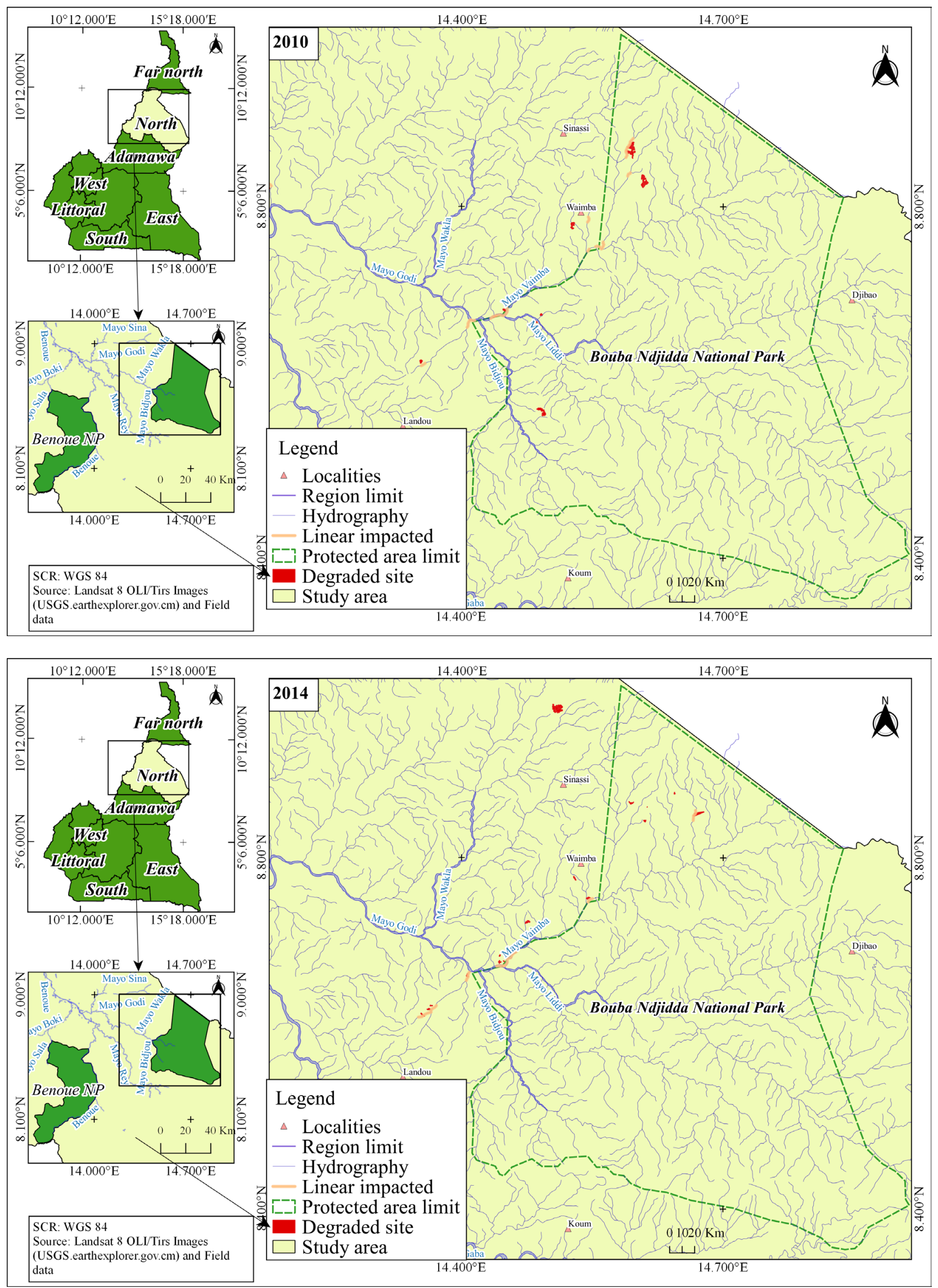

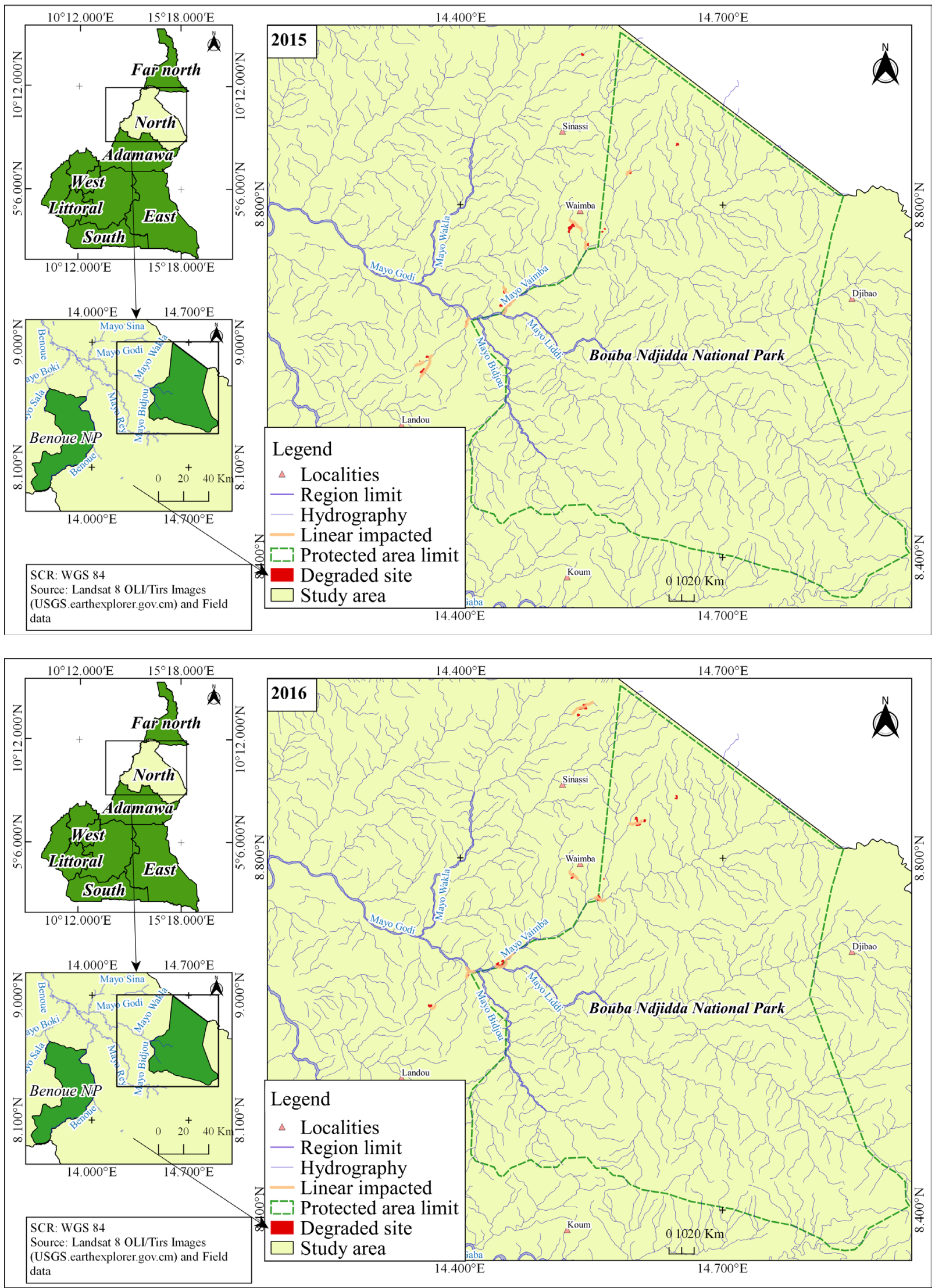

Figure 3. Mapping of exploited areas from 2009 to 2016 in the BNNP and its periphery. 
arrests, destruction of settlements, seizures of equipment used) by the conservation services of the said protected areas (National Parks and ZICs).

Alongside this degradation of the areas exploited on the hillsides, the alluvial exploitation zones, which are segments corresponding to the linear of the exploited rivers, have been highlighted. It emerges that a cumulative linear of about $143 \mathrm{~km}$ has been exploited in the BNP. It also appears that the year 2009 and 2010 were particularly active with more than $30 \mathrm{~km}$, followed by 2014 and 2015 with more than $25 \mathrm{~km}$. The exploited rivers are: Benue and its main tributaries.

With regard to the BNNP, in 2009, it is estimated that about 84 hectares are degraded by this activity. It reached the peak of 341 hectares in 2010 before experiencing an inflection in 2015 with 167 hectares of surfaces degraded by illegal gold panning. A revival of this activity is observed in 2016 especially within the BNNP about $13 \mathrm{~km}$ from the border with Chad where these nationals are mainly installed. The degraded area in 2016 is estimated at about 216 hectares. This situation will seriously jeopardize the cross-border initiative of having a concerted and sustainable management of the national parks of the Bouba Ndjidda-Sena Oura Binational Complex (Chad).

In parallel with this degradation of the areas exploited on the slopes, are highlighted the alluvial exploitation zones which are segments corresponding to the linear of exploited watercourses. It emerges that a linear of about $73 \mathrm{~km}$ was exploited in the BNNP, for the year 2010 which was particularly active $22 \mathrm{~km}$, followed by the year 2015 with $14 \mathrm{~km}$. The most exploited rivers are: Mayo Rey and its tributaries: Mayo Waimba, Mayo Bidjou, Mayo Tokormaye, Mayo Tokor, Mayo Godi, Mayo Liddii, Mayo Bietou...

\subsection{The Impact on Biological Resources of These Protected Areas}

Gold panning activity has negative impacts on the environment. In fact, harvesting techniques linked to this activity have detrimental repercussions for natural resources. They are straightforward: the deforested and worked surfaces of the farms lead to the fragmentation and fragmentation of the plant landscape and of which the habitat of the wild fauna, the deforestation by a felling of the trees entails the destruction of the vegetal landscapes; the destruction of forest galleries due to alluvial exploitation, compaction and leaching of soils that can permanently prevent revegetation (Figure 4). Soils are delivered to leaching and degradation through the gold mining process. Gold miners transform the gold-bearing sites with successions of holes and piles of land anarchically arranged in the landscape. The linear of exploited watercourses is subject to impact, due to the total destruction of aquatic ecosystems, the associated environmental pollution, the modification of the hydrographic network. In an indirect way, the disturbance of the habitat of the fauna strewn with holes prevents the mobility of the wild fauna and constitutes a danger for this fauna which can be trapped in these pits. Gold panning intensifies the poaching of wildlife, which is 

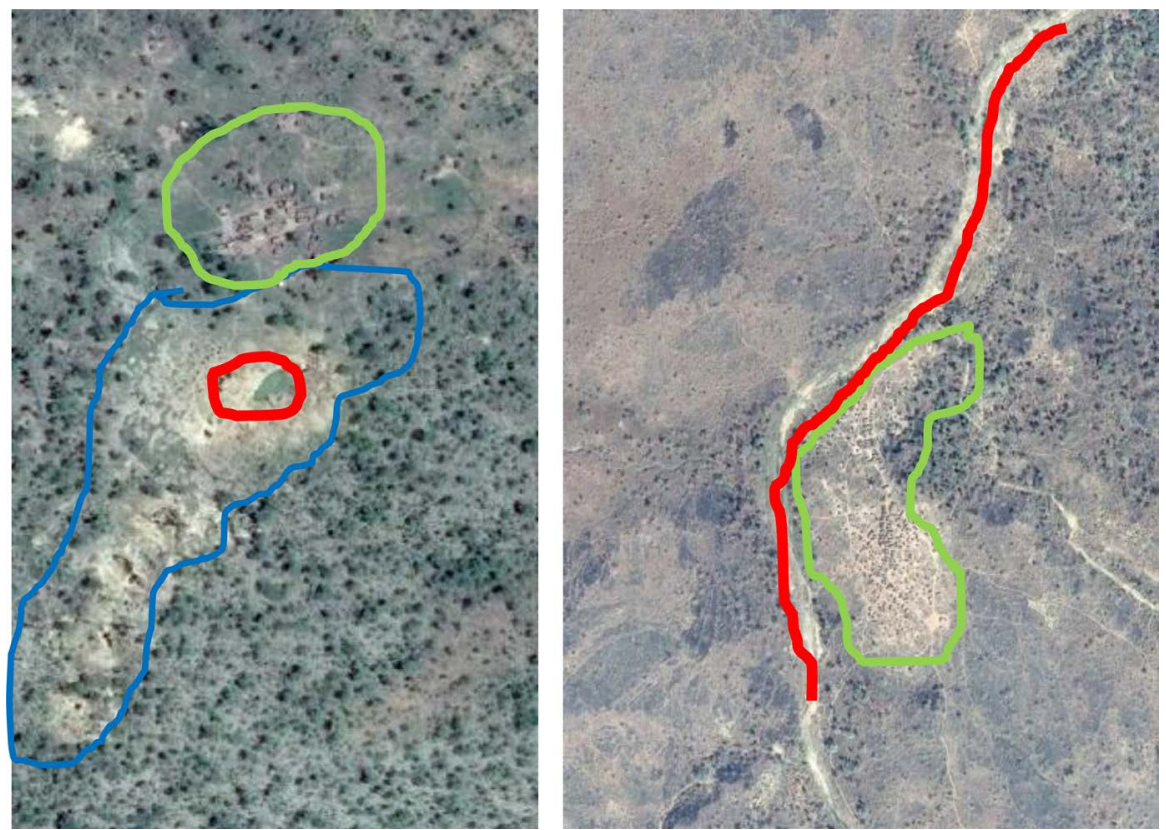

Figure 4. Gold panning sites, exploited zone completely stripped in red (on the left, a crater open on the slope, on the right the alluvial exploitation), in green color the camps of the miners.

their source of animal protein. Mercury pollution used to amalgamate gold, fuels that power generators and motor pumps pour and flow into the water. Muddy water escapes from the farms disturbing the breathing and reproduction of fish...

\section{Discussion}

Approximately 7160 gold miners for about thirty sites scattered in the two protected areas and their peripheries. These figures are estimates more or less close to reality, because it is always difficult to count the miners who are also very mobile. The activity that started timidly has grown over time. Thus, as of 2009, it is estimated that about 611 hectares are degraded by this activity. It reached the peak of around 972 hectares in 2014 before experiencing a fall in activity in 2016 with approximately 364 hectares of land degraded by illegal gold panning. $217 \mathrm{~km}$ of linear main rivers and their tributaries are affected by placer gold mining.

The environmental consequences of gold washing are numerous, among others: the fragmentation and fragmentation of the plant landscape, the habitat of wildlife, the destruction of forest galleries, the leaching of soils, the modification of the hydrographic network, pollution by the mercury and the fuel poured into the waters, the intensification of the poaching of the fauna... These effects of gold washing on the environment were observed well locally [15] than elsewhere [2]; in the Sahara [16], in Suriname [17] and in Guyana [14].

Remote sensing and GIS are indispensable tools for monitoring the extension of gold panning. They make it possible to precisely locate exploited and abandoned sites. Gong and Al used geomatics to monitor the forests of Guyana [14]. 
However, high resolution sensors would be more suitable for regular monitoring of active sites.

\section{Conclusion}

This article, which focuses on "advancing the mining front (gold panning) in and around the protected areas", aimed to draw up an inventory of the progress of the mining front (gold panning) in the Bénoué National Park and Bouba-Ndjidda. It appears that gold washing activities are carried out on the slopes and on the banks as well as in the beds of many rivers running through these two protected areas. Thus the Mayo Rey, the Benue and their tributaries are stormed by gold miners. The mapping of the pressures exerted by this activity made it possible to note that $143.8 \mathrm{~km}$ and $73.8 \mathrm{~km}$ of cumulative linear were exploited respectively in the BNP and the BNNP. The areas degraded by gold panning are more important in Bénoué than in Bouba Ndjidda. Thus, between 2009 and 2016, the most exploited area in Benoue is that of 2014 with 735.6 hectares while it is 341.6 for Bouba Ndjidda in 2010 which are particularly active years. Also, more than 30 gold panning sites were visited, including 16 in the PNB and 14 in the BNNP. This study is alert for protected area managers who have the imperative to conserve resources. They will have to rely on spatial data to monitor their conservation territory.

\section{Conflicts of Interest}

The authors declare no conflicts of interest regarding the publication of this paper.

\section{References}

[1] Beguima Narma, L.F. (2013) Exploitation of Gold in the Betare-Oya's Subdivision: between Stakeholder Practices and Sustainable Development. M.Sc. Thesis, Université de Ngaoundéré, Ngaoundéré, 192 p.

[2] Grégoire, E. and Gagnol, L. (2017) Gold Rushes in the Sahara: Gold Washing in the Tenere Desert and the Aïr Massif (Niger). http://echogeo.revues.org/14933 https://doi.org/10.4000/echogeo.14933

[3] Linares S., Joubert, P. and Gong, V. (2008) Against Illegal Gold Mining: Remote Sensing. Natural Spaces, 23, 32-33.

[4] Sangaré, O., Mundler, P. and Ouedraogo, L. (2016) Informal Institutions and Local Governance in Artisanal Gold Mining. A Case Study in Burkina Faso. Governance Review, 13, 53-73. https://doi.org/10.7202/1039240ar

[5] Raimond, C. (2015) Agrobiodiversity and Landscape Dynamics. From Fields to Conservation Territories (Haute Bénoué, Cameroon). University Paris 1 PanthéonSorbonne, Paris, 246 p.

[6] Saleh, A. (2012) A Model and Its Setback: The Co-Management of the Waza and Benoue Biosphere Reserves in Northern Cameroon. Ph.D. Thesis in Geography, University of Maine, $337 \mathrm{p}$.

[7] Seignobos, C. (2010) A Land Negotiation Not Found? The Example of Mayo-Rey in Northern Cameroon. Armand Colin, Paris, 657-677. 
[8] Terdel (2007) Socio-Economic Study of the UTO of Bouba N'djidda. Report for the WWF, $196 \mathrm{p}$.

[9] Donfack, P., Tsakem, S.C., Yello, Y. and Kinkeu, D.G. (2001) Phyto-Ecological Study of the Bouba-Ndjidah National Park in Relation to Wildlife. Study Report, WWF/PSSN, $70 \mathrm{p}$.

[10] Brabant, P. (1972) Explanatory Note of the Reconnaissance Soil Map of Cameroon, Rey-Bouba at 1/200 000. ORSTOM, Yaoundé.

[11] Segalen (1967) Soils and Geomorphology of Cameroon. Vol. 5, 137-147.

[12] Suchel (1972) The Distribution of Rainfall and Rainfall Patterns in Cameroon, Contribution to the Study of the Climates of Tropical Africa. CEGET, Federal University of Cameroon, Bordeaux, 287 p.

[13] Brabant, P. and Humbel, F.X. (1974) Information Sheet $N^{\circ}$ 51, Soil Map of Cameroon, Polished at 1/200,000. ORSTOM, Yaoundé, $107 \mathrm{p}$.

[14] Gond, V. and Brognoli, C. (2005) Remote Sensing and Spatial Planning: Location and Identification of Gold Washing Sites in French Guyana. Wood and Forest of the Tropics, 5-13.

[15] Narké, J.C. (2017) Habitat Fragmentation and Breakdown of Ecological Connectivity between Benue and Faro National Parks. M.Sc. Thesis, University of Maroua, Maroua, $14 \mathrm{p}$.

[16] Peterson, G.D. and Heemskerk, M. (2001) Deforestation and Forest Regeneration Following Small-Scale Gold Mining in the Amazon: The Case of Suriname. Environmental Conservation, 28, 117-126.

[17] Moull, D., Saffache, P. and Transler, A.L. (2006) Gold Panning in French Guyana: Synthesis of Knowledge. 